\title{
Interseccionalidade e encruzilhada: exuzilhamentos
}

\author{
Intersectionality and crossroads: exuzilhamentos
}

Cayo Honorato ${ }^{\mathrm{a}, *}$ (1D

Suene Honorato ${ }^{b}$ (D)

\begin{abstract}
RESUMO: A partir de questões suscitadas pelas palestras de Maria Aparecida Moura e Bianca Santana no encontro Decolonialidade e Ciência da Informação: veredas dialógicas, o artigo faz uma comparação inicial entre três conceitos distintos, mas correlatos: interseccionalidade, encruzilhada e exuzilhada. Para isso, toma como referência principal textos de Patricia Hill Collins e Sirma Bilge, Leda Maria Martins e Cidinha da Silva, respectivamente. Nesse percurso, avalia o modo como cada conceito busca representar a complexidade e heterogeneidade de experiências marginalizadas ou rarefeitas. Considerando alguns dilemas do primeiro conceito, entende que os dois últimos podem nos sugerir um conceito não essencialista de representação. Em todo caso, o artigo marca o início de uma discussão, aberta a outros caminhos e transformações, sublinhando o diálogo como "processo vital móvel".
\end{abstract}

Palavras-chave: Interseccionalidade; Encruzilhada; Exuzilhada; Representação.

ABSTRACT: Based on issues raised by Maria Aparecida Moura and Bianca Santana's lectures at the meeting Decoloniality and Information Science: dialogical paths, the article makes an initial comparison between three distinct but related concepts: intersectionality, crossroads and exuzilhada. For this, it takes as its main reference texts by Patricia Hill Collins and Sirma Bilge, Leda Maria Martins and Cidinha da Silva, respectively. Along the way, it assesses how each concept seeks to represent the complexity and heterogeneity of marginalized or rarefied experiences. Considering some dilemmas of the first concept, it understands that the last two can suggest a non-essentialist concept of representation. In any case, the article marks the beginning of a discussion, open to other paths and transformations, underlining the dialogue as a "moving vital process".

Keywords: Intersectionality; Crossroads; Exuzilhada; Representation.

a Departamento de Artes Visuais, Universidade de Brasília, Brasília, DF, Brasil.

b Departamento de Literatura, Universidade Federal do Ceará, Fortaleza, CE, Brasil.

*Correspondência para/Correspondence to: Cayo Honorato. E-mail: cayohonorato@unb.br.

Recebido em/Received: 30/06/2021; Aprovado em/Approved: 04/10/2021.

Artigo publicado em acesso aberto sob licença CC BY 4.0 Internacional ()(i) 


\section{INTRODUÇÃO}

Entre os dias 01 e 02 de outubro de 2020, aconteceu, em formato remoto, o encontro Decolonialidade e Ciência da Informação: veredas dialógicas'. Na primeira sessão de palestras, Maria Aparecida Moura e Bianca Santana problematizaram a exclusão ou invisibilização de perspectivas que fogem ao sistema hegemônico produzido pelo (neo)colonialismo. Ambas as palestrantes partiram da referência a Exu, orixá mensageiro entre temporalidades, lugares e mundos, em contraposição à noção linear e homogeneizadora do conhecimento pressuposta pela perspectiva colonial. Moura propôs "exuzilhar saberes". O neologismo criado por Cidinha da Silva (2018) foi evocado como imagem para a produção de "pluriepistemologias", nas quais abertura e reencontro com o "outro", a alteridade e o diverso, seriam práticas possíveis. Santana reivindicou a ideia de tempo cíclico, não linear, protagonizada por Exu, na relação com a memória dos traumas vividos por sujeitos escravizados, de onde o passado poderia emergir para ser devidamente enterrado. Ressaltou a produção de informação e conhecimento por negras e negros no Brasil, invisibilizada por um regime epistemicida, que privilegia o documento escrito como fonte para a pesquisa historiográfica.

Neste artigo, pretendemos desdobrar algumas linhas do debate suscitado pelas duas palestrantes, comparando o modo como três conceitos distintos, mas correlatos, buscam visibilizar experiências marginalizadas ou rarefeitas. São eles: o conceito de "interseccionalidade", a partir do livro homônimo de Patricia Hill Collins e Sirma Bilge (2016); o de "encruzilhada", na perspectiva de Leda Maria Martins (1997) em Afrografias da memória; e finalmente o de "exuzilhada", a partir do livro Um exu em Nova York, de Cidinha da Silva. Collins, professora da Universidade de Maryland, é uma referência incontornável para a história intelectual da interseccionalidade. No livro escrito em colaboração com Bilge, professora na Universidade de Montreal, as autoras tomam como ponto de partida o "trabalho duro" que o diálogo entre diferenças pressupõe, como aquilo que a interseccionalidade deve realizar. Martins é poeta, congadeira e professora aposentada da Universidade Federal de Minas Gerais, sendo reconhecida principalmente como pensadora do teatro brasileiro e da tradição dos reinados negros. No livro Afrografias, a encruzilhada é o operador conceitual principal. Silva é escritora, além de pesquisadora das relações raciais contemporâneas no Brasil. Seu livro reúne pequenos contos, em que as manifestações de Exu se multiplicam.

Nossa hipótese é que, embora o caráter correlato desses conceitos nos permita pensálos como complementares, algumas diferenças entre eles merecem ser notadas. Em resumo, se a abordagem da complexidade é para a interseccionalidade um elemento importante de seu programa crítico-normativo, assim como de seu compromisso com a justiça social, uma série de fatores - de sua atenção desigual para os eixos que devem

\footnotetext{
${ }^{1} \mathrm{O}$ encontro foi realizado pelo Departamento de Biblioteconomia da Universidade Federal do Rio de Janeiro (UFRJ), pelo Programa de Pós-Graduação em Ciência da Informação e Programa de Pós-Graduação em Ciência, Tecnologia e Sociedade da Universidade Federal de São Carlos (UFSCar) e pelo Programa de Pós-Graduação em Ciência da Informação da Escola de Comunicações e Artes da Universidade de São Paulo (USP). Disponível em: <https://bit.ly/3qyipg7>. Acesso em: 13 jun. 2021.
} 
ser considerados a uma assimilação da abordagem que ela pretende multiplicativa por um modelo aditivo - termina complicando suas intenções. Em todo caso, é a redução da complexidade pela "visualidade irresistível" das metáforas interseccionais, sujeita aos limites representacionais que estas lhe oferecem, o que nos parece menos visível. Neste contexto, a representação é pensada enquanto inscrição de experiências heterogêneas em um mundo em comum. Por meio da inscrição, estas experiências se tornam visíveis e compartilháveis; porém, de maneira inevitavelmente editada pela representação. Por sua vez, os conceitos de encruzilhada e exuzilhada, através de operadores como analogia e deslocamento, pareceram nos oferecer alternativas àquela "multiplicidade aditiva", aproximando-se talvez com mais propriedade a uma ideia de representação não essencialista das experiências e realidades em questão.

\section{INTERSECCIONALIDADE E REPRESENTAÇÃO}

Segundo Patricia Hill Collins e Sirma Bilge (2016; 2021), ${ }^{2}$ a interseccionalidade é uma ferramenta de acesso, análise e compreensão da complexidade no mundo e nas pessoas. As autoras também a descrevem como um "modo de entender" ou um "dispositivo heurístico" - o que destaca sua dimensão metodológica. A complexidade em questão diz respeito ao modo como os sistemas ou relações de poder são construídos por uma combinação variável de fatores, domínios e dimensões, que atuam conjuntamente em contextos históricos, intelectuais e políticos particulares, situando aquilo que sentimos, pensamos e fazemos. As situações em que ela pode ser observada são diversas: das organizações ao "mundo", passando pelo poder estatal e pelo capitalismo global - como demonstram os exemplos repassados no livro. Mas é na "vida das pessoas" - das políticas identitárias coletivas às biografias individuais que ela encontra um foco. Notadamente, é na experiência heterogênea das mulheres negras, especialmente, ou das mulheres "de cor", de forma mais ampla, que a complexidade visada pela interseccionalidade tem seu objeto primordial. ${ }^{3}$ Dessa perspectiva, a vida de pessoas sujeitas à desigualdade social é melhor entendida como sendo modelada ou produzida "não por um único eixo de divisão social, [... ] mas por muitos eixos que trabalham juntos e influenciam um ao outro" (Collins, Bilge 2016, p. 2 e 11 , tradução nossa). ${ }^{4}$

Descrever essa complexidade é também um elemento do programa assumido pela interseccionalidade que, no entanto, dificulta a própria aplicação dessa ferramenta. Embora afirmem que a interseccionalidade pode "assumir muitas formas diferentes" (Collins, Bilge 2016, p. 4), dentre aqueles "muitos eixos", há os que aparecem como eixos principais, de maneira mais recorrente: raça, gênero e classe social. Muitas vezes,

\footnotetext{
2 O livro de Collins e Bilge tem duas edições em inglês, sendo a segunda (de 2020) uma atualização da primeira (de 2016). No Brasil, a edição de 2021 se baseia na segunda edição. Em função das diferenças entre os textos da primeira edição em inglês e da edição brasileira, aos quais tivemos acesso, optamos por manter ambas as referências.

3 Em Collins e Bilge (2016), o termo "mulheres de cor" abarca mulheres negras, chicanas, asiáticoamericanas e indígenas. Ele também procura contemplar uma genealogia múltipla da interseccionalidade, irrestrita ao feminismo negro.

${ }^{4}$ Todas as citações de referências em língua estrangeira têm tradução nossa.
} 
os dois primeiros enfatizam um contraponto às explicações que os tratam, entre outros, como simples complementos (add-ons) do terceiro. Nesse sentido, de uma perspectiva interseccional, a desigualdade econômica não é só uma questão de classe, mas está conectada principalmente a questões de raça e gênero. Outros eixos apontados pelas autoras são: cidadania, sexualidade, idade, nacionalidade, deficiência, etnicidade e religião - em ordem aproximada de recorrência. Eles integram séries variáveis, onde nem todos os eixos aparecem juntos. Em todos os casos, porém, as séries começam com raça e gênero, nem sempre acompanhados por classe. Em alguns casos, elas terminam com a expressão "entre outros". No cap. 1, a série mais curta aparece na p. 11: "Os espetáculos de mídia massiva e eventos associados apresentam importantes roteiros de gênero, raça e nacionalidade que trabalham juntos e influenciam um ao outro". Enquanto a mais longa, na p. 27: "Além disso, raça, classe, gênero, sexualidade, idade, deficiência, etnicidade, nacionalidade e religião, entre outros, constituem sistemas de poder entrelaçados, que se constroem ou se intersectam mutuamente" - onde falta cidadania, por exemplo.

Essa variação - no sentido de uma atenção desigual para os diferentes eixos em questão - depende, naturalmente, do contexto ou situação que estão sendo considerados: eventos esportivos, articulações entre governo e capitalismo, relações entre movimentos sociais e identidades nacionais, formações culturais etc. Mas ela, em parte, tem uma explicação histórica, relativa ao surgimento, entre 1960 e 1970, nos Estados Unidos, do que viria a ser chamado de interseccionalidade, no âmbito dos movimentos sociais protagonizados por mulheres de cor, a partir da constatação de que essas mulheres eram desigualmente tratadas ou, no caso das mulheres negras, duplamente discriminadas, eis que sua marcação de raça era desconsiderada pelo movimento feminista, assim como sua marcação de gênero pelo movimento negro. Sendo assim, é possível dizer que essa ferramenta tem mais experiência para perceber e analisar cruzamentos entre raça, gênero e classe, do que entre estes e outros eixos. No entanto, quando sua pretensão de "assumir muitas formas diferentes" se cruza com aquela atenção desigual, a interseccionalidade pode, inadvertidamente ou não, tratar outros eixos como acréscimos; como se cidadania, sexualidade, idade etc. fossem epifenômenos dos eixos predominantes. Tal situação desafiaria esse dispositivo de forma semelhante a como ele próprio desafiou as explicações limitadas por uma lente de classe, por exemplo; por mais que raça e gênero sejam lentes majoritárias para se analisar experiências marginalizadas diversas.

O modo como os diferentes eixos ou lentes "trabalham juntos" também merece consideração. A propósito, segundo Jennifer C. Nash (2019, p. 9), esse é um "debate persistente" para o feminismo negro. Collins e Bilge (2016) empregam o termo "relacionalidade" para abarcar as várias formas em que a interseccionalidade pode ser encontrada: coalizão, diálogo, conversação, interação e transação. Contudo, ao abraçar um enquadramento de tipo "e/e" (both/and frame), em contraponto a uma lente de tipo "ou/ou" (either/or lens), a perspectiva de que os diferentes eixos "influenciam um ao outro" termina sendo reduzida, em vez de apenas representada. Afinal, a ideia de que os diferentes eixos se somam, à maneira de uma justaposição, não contempla o que Deborah King (apud Collins, Bilge 2016, p. 76; apud Nash 2019, p. 
8) chamou de "ameaça múltipla" (multiple jeopardy), ou ainda, de uma "interação dinâmica" das estruturas de dominação, cujo modelo seria multiplicativo mais do que aditivo. Ainda segundo King, "a fórmula equivalente [a isso] é racismo multiplicado por sexismo multiplicado por classismo". A par da referência (novamente) aos eixos principais, no entanto, essa interação se dá, simultaneamente, entre uma multiplicidade de eixos, produzindo a cada vez situações específicas de discriminação, opressão e violência, que precisariam ser descritas e reagregadas, mais do que postuladas.

Na p. 15, por exemplo, Collins e Bilge (2016, grifo nosso) afirmam que "a análise interseccional demonstra como a estrutura da diferença salarial (inequality gap) é simultaneamente racializada e generizada para as mulheres de cor". Mas não sabemos como ela demonstra essa correlação, já que o argumento simplesmente nos remete ao dado estatístico que, inegavelmente, comprova as diferenças em questão. Nossa intenção, obviamente, não é invalidar o questionamento da diferença salarial, muito menos sua racialização e generização, tampouco ignorar os corpos explorados pelo capital, mas sublinhar neste ponto que uma delimitação da interseccionalidade pela sociologia crítica tradicional pode comprometer sua pretensão analítico-descritiva. $\mathrm{Na}$ p. 16, as autoras afirmam que o enquadramento interseccional "revela" como os diferentes eixos "se relacionam de maneiras complexas e interseccionais para produzir a desigualdade econômica". A explicação (explanans), nesse caso, além de algo tautológica, substitui em última análise o que deve ser explicado (explanandum) (cf. Latour 2012, p. 47, 60, 98 e 148). Não sabemos como, isto é, por meio de quais conexões materiais, os eixos se relacionam; somos remetidos à passagem do estado de bemestar social para o neoliberalismo como um "fator preponderante" - o que termina produzindo uma explicação contraditoriamente unívoca e inerte, trazida de outro lugar e que tende a desaparecer com aquela "interação dinâmica".

Essa contradição, portanto, também dificulta a abordagem da complexidade (em sentido multiplicativo) pela interseccionalidade. Dissemos que sua atenção desigual para os diferentes eixos tem uma explicação histórica. Mas o modo como a relacionalidade dos eixos é simplificada por um modelo aditivo também pode ter uma explicação política, se não político-institucional. Ainda segundo Collins e Bilge, à medida que a interseccionalidade é institucionalizada nas universidades americanas, os debates em torno de sua definição problematizam suas possibilidades. Perguntas sobre quais eixos devem ser considerados, ou sobre qual metodologia empregar para se compreender o modo como os diferentes eixos interagem, são referidas pelas autoras como "espinhosas"; de algum modo, porém, elas seriam respondidas pela própria interseccionalidade, "atenta ao modo como as relações de poder moldam o conhecimento" (Collins, Bilge 2021, p. 115). Neste ponto, parece haver um dilema entre, de um lado, conferir à interseccionalidade uma extensão que the aproxime efetivamente da complexidade, abrindo-a para uma multiplicidade empírica de situações de discriminação, e de outro, proteger os usos dessa ferramenta, buscando preservar sua especificidade por meio daquilo que Nash (2019, p. 4) chamou de uma prática "defensiva" (defensiveness), que retém de maneira algo proprietária ou normativa a prioridade prévia de determinados eixos de opressão. 
Certamente, abordar a complexidade é também um requisito para se fortalecer as práticas democráticas e suas demandas por justiça social. Nesse caso, a resposta aos dilemas da interseccionalidade assume uma dimensão tática, que reconhece o problema da representação da complexidade. Collins e Bilge (2016, p. 133) entendem que as identidades mobilizadas pelas lutas de grupos desfavorecidos, por exemplo, "não são fundamentalmente fixas e imutáveis"; noutros termos, que elas são complexas, permitindo inclusive observar como funcionam as alianças entre as diferenças. Reconhecendo, no entanto, que a própria noção de identidade reduz de algum modo essa complexidade, as autoras recorrem ao trabalho de Gayatri Spivak para afirmar que, ao ressaltar um ou mais aspectos, eixos ou marcações da "identidade" de um indivíduo ou grupo, a interseccionalidade pratica na verdade um "essencialismo estratégico", que "performa identidades múltiplas, que diferem de um contexto ao outro" (Collins, Bilge 2016, p. 133). Aparentemente, sem esse essencialismo, os diferentes indivíduos e grupos não conseguiriam se reunir e construir coalizões, mas como se dá sua performação? Referindo-se à ideia de "ameaça múltipla" ou "interação dinâmica" de Deborah King, Collins e Bilge (2021, p. 104) afirmam que esses termos "[...] ajudam [King] a evitar armadilhas das abordagens aditivas". Em outro momento, porém, afirmam que a adição de categorias de análise é o que "proporciona complexidade à interseccionalidade" (Collins, Bilge 2021, p. 113). Nossa hipótese é que o modelo aditivo persiste mesmo no que se pretende multiplicativo, na forma do que poderíamos chamar de uma "multiplicidade aditiva".

Uma forma de apresentá-la é retomando as metáforas empregadas por Kimberlé Crenshaw (1989) para caracterizar a interseccionalidade. A autora recorre à imagem de um cruzamento entre avenidas para se referir ao modo como os efeitos de múltiplas formas de discriminação se intersectam na experiência de indivíduos ou grupos marginalizados: "Se um acidente acontece em um cruzamento, ele pode ser causado por carros vindos de qualquer uma das avenidas e, às vezes, de todas elas". Endereçada à incapacidade do sistema jurídico para assimilar questões de justiça social, a metáfora chama a atenção para a necessidade de se construir "quadros" (frames) que nos permitam, a nós e ao sistema jurídico, enxergar a situação daqueles indivíduos e grupos. Para ela, trata-se de um problema de "enquadramento" (framing), uma vez que "não podemos resolver um problema, se nós não enxergamos esse problema". Noutra metáfora, ela nos sugere imaginar um porão onde estivessem, umas sobre as outras, todas as pessoas desfavorecidas em razão de sua raça, gênero, classe, sexualidade, idade e/ou capacidade física. Quanto mais fatores as desfavorecem, mais próximas do chão elas estão, de tal modo que as pessoas afetadas por somente um fator ficam mais próximas do teto, podendo eventualmente acessar, através de uma portinhola, o piso superior onde vivem os que não são afetados por qualquer desvantagem. Assim, "aquelas que precisam carregar vários fardos geralmente são deixadas em baixo, a não ser que elas possam se inserir nos grupos aos quais é permitido se espremer pela portinhola" (grifo nosso).

Para além das questões políticas, podemos aqui considerar algumas questões operacionais ou cognitivas. Se por um lado as metáforas nos oferecem lentes para enxergar o problema - o que ajuda a compreender porque a interseccionalidade, em 
sua "visualidade irresistível" (Nash 2019, p. 11), se tornou a principal teorização sobre o entrelaçamento das estruturas de dominação -, por outro elas reiteram o modelo aditivo, segundo o qual os diferentes eixos se justapõem. Além disso, sugerem que o essencialismo estratégico pressupõe uma negociação entre os diferentes eixos que, para benefício de uma possível coalizão, tenderia a sacrificar a multiplicidade dos cruzamentos em questão, se não a própria experiência das pessoas que os suportam. Resta saber, no entanto, se o essencialismo é algo de que se pode entrar e sair à vontade, isto é, estrategicamente, ou se em vez disso ele não terminaria produzindo, performativamente, uma incorporação de identidades descontínuas e isoladas - o que tenderia a visibilizar identidades (aditivas) cada vez mais específicas, em detrimento de uma conversa entre diferenças (multiplicativas). Certamente, é a lógica da "portinhola" e da hierarquização entre os diferentes eixos que a interseccionalidade gostaria de eliminar. Mas é a redução da complexidade pela visualidade da metáfora, sujeita aos limites representacionais que esta lhe oferece, o que ainda nos parece menos visível. Como então contorná-la?

\section{REPRESENTAÇÃO E ENCRUZILHADA}

Em Afrografias da memória, Leda Maria Martins (1997) se propõe a traduzir ou transcriar - a partir do entrelaçamento da oralidade com a letra - a "complexa tessitura discursiva dos reinos negros" (Martins 1997, p. 122), especialmente o da Irmandade de Nossa Senhora do Rosário no Jatobá, em Belo Horizonte - que é seu "estudo de caso". O termo "encruzilhada" é utilizado como "operador conceitual" (Martins 1997, p. 28) para compreender trânsitos (sistêmico e epistêmico) entre sistemas simbólicos diferentes, em contraposição à noção de "sincretismo", que, para ela, reduz as possibilidades de "apreensão de outros processos constitutivos derivados dos cruzamentos simbólicos" (Martins 1997, p. 29). A noção de encruzilhada enfatiza relações inter e transculturais, que se movimentam menos por fusão ou aglutinação, do que por analogia ou deslocamento. Quando predomina o processo analógico, dois códigos se emparelham estabelecendo uma dupla significação; quando predomina o deslocamento, um código se traduz por outro, mantendo-se as estruturas simbólicas do código tradutor. As cerimônias do Reinado de Nossa Senhora do Rosário, nas quais "santos católicos são festejados africanamente" (Martins 1997, p. 31), incluem-se neste segundo processo.

De acordo com Martins, os reinos negros no Brasil se estabeleceram a partir de uma narrativa fundacional que remete ao tempo da escravidão. Das versões da narrativa registradas pela pesquisadora, depreende-se um "núcleo convergente" (Martins 1997, p. 45), centrado no aparecimento da imagem de Nossa Senhora do Rosário sobre as águas, e no seu resgate por uma guarda de Moçambique. A narrativa fundacional, em suas várias versões, ofereceu elementos para a instauração de um "poder paralelo" (Martins 1997, p. 61) que reorganiza as relações entre os povos negros no Brasil (Martins 1997, p. 57-58) e instaura formas de sociabilidade específicas; um microsistema que opera dentro de um macro-sistema (Martins 1997, p. 47). Assim, a coroação dos reis "reterritorializa formas ancestrais de organização social e ritual" 
(Martins 1997, p. 37). As funções exercidas pelos reis, por exemplo, não se restringem à encenação anual do rito, mas se estendem à vida cotidiana das comunidades, onde são responsáveis pela resolução de conflitos diversos. Embora Reinados sejam popularmente conhecidos como Congados, essa reterritorialização os distingue, pois enquanto estes podem "existir individualmente", ligados a celebrações religiosas, os Reinados "são definidos por uma estrutura simbólica complexa e por ritos que incluem [...] a instauração de um Império" (Martins 1997, p. 31-32).

O culto à Nossa Senhora do Rosário, como informa uma das narradoras (D. Leonor Galdino), tem origem portuguesa: "a raiz mesmo veio dos branco, dos branco de lá" (apud Martins 1997, p. 51). Ao ser reinterpretado pelos negros, se transforma em "índice de resistência cultural e de sobrevivência étnica, política e social" (Martins 1997, p. 24). O rito que o encena constitui "a figuração do negro como agente no enredo que o tem por objeto" (Martins 1997, p. 49). Desse modo, um conjunto de saberes, que vinha sendo interditado no tempo da narrativa fundacional, passa a partir e por meio dela a se expressar ritualmente, instituindo a liturgia do Reinado. A esse conjunto de saberes, Martins (1997, p. 150) atribui o nome de "afrografias". Sua expressão atualiza e recria a memória de códigos africanos nas danças, cantos, instrumentos, e se inscreve sobre o código católico, sem exauri-lo ou esvaziá-lo (Martins 1997, p. 62). Essa inscrição que não exaure o código sobre o qual se expressa demonstra, justamente, aquele processo de deslocamento predominante nos Reinados, que seria uma das faces da noção de encruzilhada.

A encruzilhada, como operador conceitual, evidencia um movimento entre termos aparentemente excludentes: "Da esfera do rito e, portanto, da performance, é lugar radial de centramento e descentramento, interseções e desvios, texto e traduções, confluências e alterações, influências e divergências, fusões e rupturas, multiplicidade e convergência, unidade e pluralidade, origem e disseminação" (Martins 1997, p. 28). $\mathrm{Na}$ encruzilhada, interseções coabitam com desvios, num lugar de onde partem e aportam signos culturais em movimento, constantemente atualizados pela performance. Especificamente quanto aos rituais congadeiros, Martins (1997, p. 156) define a encruzilhada como "ponto de convergência de saberes religiosos distintos, bantos, iorubás, católicos [que] se traduz como lugar radial dessas interseções, espaço de origem e diluição, alteridade e identidade, confluência e alteração, pluralidade e individualidade". Nesta definição, mais uma vez a encruzilhada abriga pares de termos aparentemente excludentes; mas a ideia de interseção surge aqui como lugar em que esses termos são colocados em relação, operando deslocamentos e/ou analogias. A sinonímia entre encruzilhada e interseção, pensadas enquanto lugares, também ocorre neste outro trecho, acompanhada dos pares de termos em relação: "as culturas negras nas Américas constituíram-se como lugares de encruzilhadas, interseções, inscrições e disjunções, fusões e transformações, confluências e desvios, rupturas e relações, divergências, multiplicidade, origens e disseminações" (Martins 1997, p. 25). As diferenças marcadas pelos pares não se excluem, mas se colocam em diálogo, como "processo vital móvel" (Martins 1997, p. 26). 
Esse diálogo entre diferenças pode ser exemplificado se pensarmos no modo como se define a identidade racial e religiosa do/a congadeiro/a. Por ocuparem o topo da linhagem hierárquica, o rei e a rainha congos representam as nações africanas e, portanto, devem ser negros, exigência não extendia a outros reis e rainhas do Congado. Por isso, a identidade do/a congadeiro/a não pode ser definida pela cor da pele (Martins 1997, p. 165 e 171) ou pela filiação a uma tradição religiosa específica (católica, iorubá ou banto), nem ainda pela adição dos três termos (católica, iorubá e banto). Para defini-la, é preciso considerar o trânsito complexo operado entre três ou mais matrizes culturais pelos sujeitos que vivenciam o Congado, e a contínua atualização do rito na performance, que institui sua sobrevivência. O Reinado resulta, pois, em um "texto terceiro" ou "lugar-terceiro" (Martins 1997, p. 47 e 156). A encruzilhada destaca o processo de resistência dos povos de ascendência africana no Brasil, que constitui suas identidades como "um tecido e uma textura, nos quais as falas e gestos mnemônicos dos arquivos orais africanos, no processo dinâmico de interação com o outro, transformam-se e reatualizam-se continuamente [...]" (Martins 1997, p. 26).

Nas definições que destacamos, a encruzilhada é pensada por Martins como lugar que acolhe processos transformativos por analogia e deslocamento, em oposição a processos de fusão/aglutinação caracterizados pelo sincretismo. A encruzilhada pode ser o lugar das interseções, se compreendermos a interseção como processo dinâmico, em que a interação tensionada entre códigos culturais distintos permite que um modifique o outro ao mesmo tempo em que se modifica.

\title{
EXUZILHANDO A REPRESENTAÇÃO
}

Os neologismos "exuzilhar", "exuzilhada" e "exuzilhamento" têm sido utilizados por Cidinha da Silva para enfatizar a relação entre Exu e encruzilhada. A inscrição de Exu na encruzilhada, operada pelos neologismos, nos lembra que

\begin{abstract}
Nas elaborações discursivas e filosóficas africanas e nos registros culturais delas também derivados, a noção de encruzilhada é um ponto nodal que encontra no sistema filosófico-religioso de origem iorubá uma complexa formulação. Lugar de interseções, ali reina o senhor das encruzilhadas, portas e fronteiras, Éxu Elegbara, princípio dinâmico que medeia todos os atos de criação e interpretação do conhecimento (Martins 1997, p. 26).
\end{abstract}

Cidinha da Silva dedica o livro Um exu em Nova York a Leda Maria Martins, "senhora do exuzilhamento da memória e da costura da experiência" e a ela atribui o aprendizado de "circular pelas encruzilhadas" (Silva 2018a, p. 5). Os dezenove contos reunidos no volume performam essa circulação ao reunir em movimento vozes, perspectivas, lugares e tempos distintos. No prefácio, wanderson flor do nascimento 5 enfatiza que o livro nos convida a circular pelas encruzilhadas regidas por Exu, como abertura a ouvir/ler outras histórias, que podem nos levar a contar outras histórias, a ser de outros modos (apud Silva 2018a, p. 11), pois: "Talvez uma das maiores riquezas de Exu seja sua

\footnotetext{
${ }^{5}$ A opção por assinar o nome com letras minúsculas é do próprio autor.
} 
pluralidade de línguas, palavras, histórias, caminhos, memórias: uma multiplicidade de/que podemos ser" (apud Silva 2018a, p. 10).

No conjunto, as personagens do livro são representadas com marcadores diversos de raça, sexualidade, religião, nacionalidade, profissão, faixa etária, classe e capacidade. Nos contos narrados em primeira pessoa, à exceção de "Maria Isabel", a voz narrativa é feminina. Nos contos narrados em terceira pessoa, a voz narrativa acompanha pontos de vista variados: uma criança, mulheres, pessoas solitárias, pessoas que conversam, se relacionam, pessoas mortas ou à espera da morte.

O conto "Tambor das minas" rasura o esquema narrativo, na encruzilhada entre a primeira e a terceira pessoas: depois da primeira frase, endereçada a um/a interlocutor/a, marcando assim a presença de um "eu", a voz narrativa abandona a interlocução e reconta uma história que "o poeta contou de ouvir contar" (Silva 2018a, p. 69), tornando imprecisa a origem da narrativa. A palavra "minas" remete diretamente ao tambor mineiro, que bate de quatro formas diferentes (batida de lamento, batida de festa, batida de fé e batida de aviso); mas pode também evocar as "moças" que o personagem "intruso", "enxerido" ou "abusado" queria conquistar ao tocar o tambor "na encruza" (Silva 2018a, p. 69). O rapaz acreditava estar tocando uma batida de festa, mas o tambor emite o sinal de aviso ao dono, que estava em outra cidade: "Ele [o dono] escutou. Firmou o pensamento e mandou o intruso perder a força de tocar" (Silva 2018a, p. 69). O intruso entende o aviso e, com medo, devolve o tambor, que, no conto, é o próprio mensageiro entre lugares distintos, e se comunica com o dono a fim de preservar o caráter sagrado e ritual da mensagem que enuncia.

Exu é mencionado diretamente desde o primeiro conto, "I have shoes for you", em que a narradora tenta desvendar a mensagem do título, ouvida de uma pedinte no Harlem, a quem tinha dado moedas. A princípio, a narradora não entende por que a pedinte lhe oferece sapatos depois de receber moedas. Levanta hipóteses sobre a oferta: a pedinte teria achado que a narradora passava frio; a pedinte queria vender os sapatos; os sapatos seriam uma senha para uso ou tráfico de coisas. Uma das hipóteses é afastada com o pensamento de que "se tudo é dádiva na negociação com Exu, eu dei primeiro" (Silva 2018a, p. 15). A narradora segue sem desvendar o enigma, expresso pelo ditado iorubá repetido três vezes: "Exu matou um pássaro ontem com a pedra que jogou hoje!" (Silva 2018a, p. 16). Até que encontra a resposta: "Recebi os sapatospresente para firmar o pé na estrada e fazer o caminho" (Silva 2018a, p. 16).

No artigo "Olojá: Entre encontros - Exu, o senhor do mercado", nascimento (2016) comenta sobre o que chama de "mercado-ojá", regido por Exu, que mantém o axé em movimento, em contraposição à noção de troca no mercado capitalista, direcionada à acumulação. O axé, para os iorubás, seria uma força dinâmica entendida como princípio fundamental da realidade (nascimento 2016, p. 29). Manter a circulação do axé "cria laços de sociabilidade" (nascimento 2016, p. 30), em que o trabalho de cada pessoa importa, independentemente de o produto desse trabalho ser material ou não. No conto, a narradora afirma fazer a negociação com Exu, indicando que dar moedas à pedinte põe o axé em circulação. "Para a perspectiva do mercado-ojá, nada é dado 
sem contrapartida" (nascimento 2016, p. 35). Assim, a utilidade dos sapatos oferecidos pela pedinte pode ser pensada tanto em termos materiais, expressos nas hipóteses que a narradora elabora mas descarta, quanto em termos imateriais, quando ela "mata a charada". A utilidade dos "sapatos-presente" é metaforizada na pedra atirada hoje por Exu (momento em que a resposta é encontrada), que mata um pássaro ontem (momento em que os sapatos são oferecidos). O termo do enigma é o início do movimento. Os três tempos (passado, presente e futuro) se encontram na decodificação do oferecimento dos sapatos pela pedinte, que abre caminhos à narradora. Exu rege a troca para que o axé não seja acumulado, como produtos no mercado capitalista.

Mas, se há "um exu" em Nova York, é porque há outros, nos tempos e espaços narrados. Exu é o "Boca do Mundo" evocado pela narradora em "O homem da meianoite"; aparece como "sábio e cético" no final de "Mameto", diferente dos demais orixás porque "não se iludia" (Silva 2018a, p. 52). O inquice é o protótipo de uma representação não essencialista; é "signo do múltiplo e do singular" (Martins 1997, p. 27). A propósito, segundo Juana Elbein dos Santos (apud Martins 1997, p. 26-27), "[...] Èsù não pode ser isolado ou classificado em nenhuma categoria. É um princípio e, como o àse que ele representa e transporta, participa forçosamente de tudo". É "acompanhante e elemento inseparável de todos os seres naturais e sobrenaturais" (Santos 2012, p. 207). Exu se relaciona, por exemplo, às personagens que, como ele, transitam entre o mundo dos vivos e o dos mortos. Em "Maria Isabel" o narrador morto comenta o próprio velório; o afogado em "Jangada é pau que boia", estrangeiro recebido nos braços de Zumbá, acompanha os caranguejos prepararem o banquete de seu próprio cadáver (Silva 2018a, p. 59); Dona Zezé interrompe a comunicação com Deus para permanecer esquecida Dele no mundo dos vivos (Silva 2018a, p. 67); Sá Rainha, cada vez mais em "trânsito pelo país dos ancestrais", reencontra familiares que já morreram (Silva 2018a, p. 72).

Em "No balanço do teu mar", a narradora se endereça a uma mulher, de quem sente falta. A lembrança da interlocutora ausente é motivada pelas festas de largo em Salvador, lugar privilegiado da rememoração do encontro afetivo entre as personagens: "E quando vou às festas, continuo te buscando [...]. Nas esquinas de nossa menina, exuzilhamentos que nos atravessam e testam" (Silva 2018a, p. 35). Como lugar em que a narradora continua em busca do par amoroso, os exuzilhamentos sugerem uma "convivência parelha" (Martins 1997, p. 30) entre público e privado, exterior e interior, tempo e espaço, passado e presente, presença e ausência, certeza da busca e incerteza do encontro; lugar, enfim, de abertura a possibilidades e de movimento.

O conto "Sá Rainha" dialoga diretamente com o trabalho de Leda Maria Martins em Afrografias da memória, ao colocar em cena uma personagem do Reinado. Sá Rainha, já velha, falando coisas que ninguém entende, como se estivesse em "permanente estado de oração" (Silva 2018a, p. 71), veste seus adereços e caminha pelas ruas, sem cortejo. No caminho, "reconhece pessoas, lutas, desapropriações, resistência popular, tiros, medo, angústias" (Silva 2018a, p. 72). Recolhe essas impressões do mundo dos 
vivos e por elas somos informadas da movimentação social que configura o espaço percorrido pela personagem.

A referência no conto ao prédio do Muquifu, no Morro do Papagaio, permite que se tracem pontos de contato entre ficção e realidade: Sá Rainha Dona Marta, moradora do Morro do Papagaio, é uma das mulheres homenageadas no Museu dos Quilombos e Favelas Urbanos (Muquifu), no Aglomerado Santa Lúcia, em Belo Horizonte. No centro do painel pintado nas paredes do museu, o rosto da Virgem é inspirado no rosto de Dona Marta, Rainha Conga de Santa Efigênia, para representar todas as mulheres do local que, diante das dificuldades, "nunca perderam a esperança, foram sempre rainhas de suas próprias vidas" (Silva 2018b, p. 138). A fundação do Muquifu, em 20 de novembro de 2012, dia Nacional da Consciência Negra, é fruto do protagonismo dessas mulheres; um dos fundadores do museu, Mauro Luiz da Silva, evoca o "padre amigo" referido no conto (Silva 2018a, p. 72).

Acompanhando a perspectiva da personagem em trânsito entre o mundo dos vivos e o mundo dos mortos, a narrativa se põe na exuzilhada: Exu, que rege a comunicação entre os dois mundos, se inscreve na "encruza" (Silva 2018a, p. 72), em que Sá Rainha revê familiares mortos. $O$ conto destaca o encontro com os cinco filhos que "deixaram esse mundo fora do tempo" (Silva 2018a, p. 72). Ela os vê "limpos, sem furos nas roupas, sem manchas de sangue" (Silva 2018a, p. 73), os abraça e agradece a Nossa Senhora do Rosário. Depois disso,

Sá Rainha sai do abraço dos filhos. Afasta-os, carinhosa. Abaixa-se e risca o chão com um caco de telha. Pontos que ninguém ali sabe interpretar. Coloca o bastão no chão. Chora baixinho ao tirar a coroa, deposita-a na terra.

Os filhos vão desaparecendo. O povo também. Ela fica sozinha com suas insígnias de realeza depostas. Aos poucos, Sá Rainha também some no tempo. Restam o bastão e a coroa à espera de alguém.

Êh Tempo! Êh Tempo! Zaratempô! Êh Tempo! Êh Tempo! Zaratempô! Êh Tempo! Êh Tempo! Zaratempô! (Silva 2018a, p. 73)

Na cena final, vivos e mortos assistem aos gestos rituais com que Sá Rainha depõe suas insígnias. Há um movimento de fechamento e abertura, que encerra o reinado de Sá Rainha, cuja coroa herdara da mãe, e aponta para o início de um novo reinado. Sá Rainha some no tempo, e o Tempo, saudado nas últimas linhas, continua renovando seus ciclos, na direção das múltiplas possibilidades. As insígnias estão à espera de alguém. A interpretação dos pontos riscados na encruzilhada se abre à mediação de Exu. 


\section{CONSIDERAÇÕES INICIAIS}

A pergunta que nos colocamos a partir das palestras de Maria Aparecida Moura e Bianca Santana é: como os conceitos de interseccionalidade, encruzilhada e exuzilhada permitem aprofundar a percepção das experiências e realidades que procuram representar? A propósito, "evitar as generalizações que obliteram as nuances de diferença observáveis entre os diversos festejos de Reinado" (Martins 1997, p. 21) é uma das preocupações de Leda Maria Martins, que pergunta: "Como apreender, sem reducionismos teóricos, as fabulações da memória que habitam as narrativas dos congadeiros e a complexidade da representação simbólica que se pereniza no tempo, geração após geração?" (Martins 1997, p. 18-9). Nossa intenção, todavia, não é oferecer respostas definitivas. A comparação que nos propusemos fazer entre aqueles três conceitos marca o início de uma discussão, aberta a outros caminhos e transformações, sublinhando o diálogo como "processo vital móvel".

Nesse percurso, buscamos observar de que modo cada um daqueles conceitos reverbera sobre si mesmo, mas também como cada um pode incidir nos demais. No caso da interseccionalidade, percebemos que o seu dilema, entre se abrir para uma análise da complexidade e preservar suas especificidades, decorre da forma como o próprio conceito é elaborado no livro de Collins e Bilge, em que a ideia do multiplicativo termina ironicamente sendo absorvida pelo aditivo, limitando desse modo não só a capacidade analítico-descritiva da interseccionalidade, mas seu próprio compromisso com as práticas democráticas. A saída desse dilema, no entanto, não nos parece exclusivamente política, eis que dependeria da imaginação (e operacionalização) de um conceito não essencialista de representação - o que os conceitos de encruzilhada e exuzilhada nos parecem mais próximos de oferecer.

O conceito de encruzilhada, proposto por Leda Maria Martins como operador conceitual para pensar os reinos negros no Brasil, é visto como um lugar dinâmico de interseção, onde operam analogias e deslocamentos, mais do que fusões e aglutinações; onde as diferenças são postas em diálogo. Sem exaurir o código cultural que traduz, as "afrografias" dos reinos negros resultam num texto terceiro, em que a reatualização performativa é um processo vital e permanente. O procedimento de escrita de Martins opera uma tradução da tradução: consciente das diferenças entre o registro da letra e a dicção oral, busca encruzilhar esses dois regimes de produção de conhecimento. Nos contos de Cidinha da Silva, ao enfatizar a presença de Exu na encruzilhada, a exuzilhada performa multiplicidades de tempos, espaços, mundos e modos de ser. Em suas várias designações, Exu é simultaneamente "signo do múltiplo e do singular" (Martins 1997, p. 27). A análise de alguns recursos narrativos remetida à regência do orixá aponta para uma representação não essencialista das personagens, e implica leitoras e leitores na tarefa de manter o axé em circulação. 


\section{REFERÊNCIAS}

COLLINS, Patricia Hill e BILGE, Sirma, 2016. Intersectionality. Cambridge: Polity.

COLLINS, Patricia Hill e BILGE, Sirma, 2021. Interseccionalidade. São Paulo: Boitempo.

CRENSHAW, Kimberle, 1989. Demarginalizing the Intersection of Race and Sex: A Black Feminist Critique of Antidiscrimination Doctrine, Feminist Theory and Antiracist Politics. University of Chicago Legal Forum. Vol. 1989, no. 1, Article 8, p. 139-167.

[Acesso em 29 junho 2021] Disponível em: https://bit.ly/3xYtUJs

LATOUR, Bruno, 2012. Reagregando o social: uma introdução à teoria do Ator-Rede. Salvador: EDUFBA; Bauru, SP: EDUSC.

MARTINS, Leda Maria, 1997. Afrografias da memória: O Reinado do Rosário no Jatobá. São Paulo: Perspectiva; Belo Horizonte: Mazza Edições.

NASCIMENTO, wanderson flor do, 2016. Olojá: Entre encontros - Exu, o senhor do mercado. DasQuestões. Ago/set 2016. n. 4, p. 28-39. [Acesso em 22 junho 2021]. Disponível em: https://bit.ly/2Tj8NTs

NASH, Jennifer C., 2019. Black feminism reimagined after intersectionality. Durham and London: Duke University Press.

SANTOS, Juana Elbein dos, 2012. Os Nagô e a morte: Pàde, Àsèsè e o culto Égun na Bahia. Petrópolis: Vozes.

SILVA, Cidinha da, 2018a. Um exu em Nova York. Rio de Janeiro: Pallas.

SILVA, Mauro Luiz da, 2018b. Habemus Muquifu: análise da criação e das coleções do Museu dos Quilombos e Favelas Urbanos. Dissertação (Mestrado em Ciências Sociais). Belo Horizonte, MG: Pontifícia Universidade Católica de Minas Gerais. 